\title{
Efficacy of Dorsata Honey as a Mixed Carbon Source on Bacterial Cellulose Production from Acetobacter Xylinum
}

\author{
Shella Battulayan-Cacatian* and Wilfredo Mojares Estabillo \\ Faculty of the College of Teacher Education, Cagayan State University, Sanchez Mira, 3518 Cagayan Valley, \\ Philippines; allehsbc@yahoo.com,wenziejay22@yahoo.com
}

\begin{abstract}
Objectives: This study investigated the effect of the Dorsata honey concentrations on the yield of $\mathrm{BC}$, its biochemical properties, and its product cost of BC. Methods/Statistical Analysis: The experiment utilized five sets of cultures in three replicates and three samples in each replication. Data were treated using Analysis of Variance (ANOVA) and Least Significant Differences (LSD) using Completely Randomized Design (CRD) to test the disparity among the treatment means. Findings: Cellulose formation started two days after incubation when the growth medium became turbid and the surface layer of the translucent medium gradually thickened to form a thin film. The sucrose-based medium yielded the thickest A. xylinum. The media, with $\geq 50 \%$ of Dorsata honey, produced the highest weight of BC. The yield of wet BC increases with the number of fermentation days as long as the nutrient concentration is sufficient to sustain its growth. The media, having a honey concentration of up to $50 \%$, showed the highest percentage of water absorption, while the edible film cultured in pure honey showed the highest water-resistant properties. The BC content of the culture with mixed carbon source provided a more significant source of the crude fiber of around $11-12 \%$ than pure sucrose. The treatments displayed comparable solubility in all the food-grade solvents used. Supplementing the medium with Dorsata honey increases the expenditure of nata production; however, it is a potential source of fiber that is richer than the sucrose-based medium. Applications: Dorsata honey renders it suitable for nata de coco development using A. xylinum.
\end{abstract}

Keywords: Acetobacter Xylinum, Dorsata Honey, Efficacy

\section{Introduction}

Nata de coco, an indigenous dessert of the Philippines, is manufactured at an industrial scale in the country and the neighboring countries like Malaysia and Indonesia ${ }^{1}$. Production of nata de coco has increased in recent years not only for domestic markets, but also for export markets, especially Europe, Japan, the United States and the Middle East ${ }^{2}$.

Nata de coco is usually produced by the fermentation of coconut water ${ }^{1}$ or coconut milk, with a culture of A. xylinum, a gram-negative bacterium ${ }^{3}$. During the fermentation, A. xylinum needs nutrients such as carbon source to grow ${ }^{4}$. Glucose, sucrose and fructose are the most preferred carbon sources for nata production ${ }^{3}$.
In the $\mathrm{BC}$ fermentation process, nata producers generally use refined sugar as a carbon source $\mathrm{e}^{5}$. Refined sugar is pure sucrose derived from sugar cane. Several authors and researchers have utilized other sources of carbon for $\mathrm{BC}$ fermentation. $\mathrm{In}^{6}$, they applied grape pomace extract in the production of Bacterial Nanocellulose (BNC), while ${ }^{7}$ optimized $\mathrm{BC}$ production using maple syrup as a carbon source ${ }^{8}$ carried out fermentations for BC using molasses ${ }^{9}$ exploited glucose or fructose or sucrose alone and a combination of these carbon sources for BC fermentation. However, to the awareness of the researchers, no one has yet documented the utilization of Dorsata honey from wild honeybees for bacterial culture.

*Author for correspondence 
Dorsata honey is a supersaturated sugar solution, created by bees and is accessible for local consumption as a source of carbon ${ }^{10}$. It contains a mixture of several sugars, predominantly fructose and glucose $e^{11}$ and other sugars such as sucrose, maltose and some di- and trisaccharide sugars, including amino acids, enzymes, protein, vitamins, minerals, ash, organic acids and phenol compounds in varying quantities $\frac{10,12,13}{}$. These features of Dorsata honey offer a premature conclusion that it is an excellent source of mixed carbon for microbial growth.

In Cagayan Valley, wild honeybees produce honey copiously. Using Dorsata honey in the production of nata de coco will take a role of importance in the beekeeping industry. Although it is still a niche market with limited market opportunities, through this study, the demand for Dorsata honey is expected to increase as it assures the socio-economic and cultural livelihood of several local communities in Cagayan Valley.

This study, therefore, pursued an investigation on the effect of varying concentrations of Dorsata honey on the production of BC from A. xylinum.

\section{Materials and Methods}

\subsection{Experimental Design}

The study made use of a single factor experiment in a Completely Randomized Design (CRD). It investigated five sets of cultures replicated three times with three samples in each replication.

\subsection{Materials of the Study}

The study utilized the following materials: Coconut milk, refined sugar, glacial acetic acid, mother liquor, water, honey, cheesecloth, wooden spoon, rubber band, plastic tray size $20 \times 15 \mathrm{~cm}$, plastic pail, plastic pitcher, weighing scale, $\mathrm{pH}$ meter, Digital Caliper.

\subsection{Bacterial Cellulose Production}

The researchers obtained the A. xylinum culture at the Food Processing Center of the Cagayan State University at Sanchez Mira. Next, they mixed one kilogram of grated coconut meat with five liters of purified water; it was squeezed and filtered to remove the residues. After that, they added five liters of water to the coconut milk extract. The ratio of refined sugar and honey was according to the amount specified in the treatments. Then the researchers added $250 \mathrm{ml}$ of glacial acetic acid and five liters of mother liquor containing the A. xylinum culture to the mixture. They mixed the formulation thoroughly to dissolve the ingredients. Afterwards, they filled $1 \frac{1 / 2}{2}$ liters of the formulation into a plastic tray measuring $25 \times 16 \times 9 \mathrm{~cm}$. Subsequently, they covered each plastic tray with paper and tightened with a rubber band. They incubated the cultures statically in a room where the temperature is $28-32^{\circ} \mathrm{C}$ and left undisturbed for 14 days.

\subsection{Harvesting the Nata de Coco}

The nata de coco produced was harvested after 14 days. The researchers removed the film of the nata at the bottom. Then they washed the harvested nata thoroughly in running tap water until the $\mathrm{pH}$ is roughly at the neutral point of 7 and to eliminate the sour taste.

\subsection{Data Gathering Procedure}

- Thickness: The thickness (mm) of the BC film was measured using a Digital Caliper.

- Wet Weight: The freshly gathered BC film was lifted and placed in a strainer to drip off the excess water completely for one minute. Then it was weighed to get the wet weight in grams. To determine the damp and dry weights, the researchers used a weighing balance having $0.01 \mathrm{mg}$ reproducibility.

- Dry Weight of BC: One kg of raw nata de coco was weighed. Then the nata was sun-dried by spreading on a baking tray until completely dry. Subsequently, the weight of BC was computed immediately after drying. The dry weight was calculated using the following formula:

Dry Weight $=\frac{\text { The dry weight of bacterial cellulose }(\mathrm{g})}{\text { The wet weight of bacterial cellulose }(\mathrm{g})} \times 100$

After drying, the BC films were immediately weighed to minimize possible rehydration. The dry weight was determined using a weighing balance with $0.01 \mathrm{mg}$ reproducibility.

- Water Absorption Capacity: The BC film was cut into $1 \times 1$ inch. One $\mathrm{kg}$ of raw nata from each treatment was submerged in purified water for nine days at room temperature. After nine days, the samples were carefully rinsed and weighed. The percentage of after absorption was computed using the formula below:

$$
\mathrm{W}_{(\%)}=\frac{\mathrm{W}_{2}-\mathrm{W}_{1}}{\mathrm{~W}_{1}} \times 100
$$


Where $\mathrm{W}_{(\%)}=$ Percent water absorption (final percentage increase in weight of the tested sample).

$\mathrm{W}_{1}=$ Weight before submerging in water.

$\mathrm{W}_{2}=$ Weight after removing from water.

- Solubility: The researchers determined the relative solubility of the produced nata de coco by suspending the nata de coco for ten days in the different foodgrade solvents.

- Product Cost: The product cost was determined by computing all the expenditures spent on buying the materials. The basis for the price of the honey-infused nata de coco was on the specific measurements of the materials used in the conduct of the study.

\subsection{Statistical Analysis}

The data were treated using an Analysis of Variance (ANOVA) to determine whether the treatments show a significant difference from each other. Least Significant Differences (LSD) was used to determine which treatment means differ significantly in the .01 and .05 levels of significance.

\section{Results and Discussion}

\subsection{Thickness of Nata de Coco}

In all the treatments, cellulose formation began only on the third day of incubation when the growth medium became turbid and the surface layer of the translucent medium gradually thickened to form a thin film. This finding supports the report of $\frac{14}{}$ that they have not observed any visible nata formation in the initial stages of up to 2-3 days of incubation. However, the rate of BC formation differed in the five treatments.

Table 1 discloses that when A. xylinum was cultured in the medium using pure sucrose and different concentrations of honey for 5-9 days, the thickness of nata is not significantly different in all the treatments. On the $13^{\text {th }}$ day, a significant difference existed in the formulations. The medium containing sucrose as the sole carbon source obtained the maximum depth of nata. The bacteria were able to make this transition effectively, as evidenced by the considerable yield of nata.

The yield of nata reduces with the increase of honey concentration to a ratio higher than $1 / 2$. Findings reveal that the thickness and wet weight of nata are positively correlated. This finding justifies the report of $\frac{14}{4}$ that the depth of nata has a direct effect on the amount of water it can hold, which in turn affects the heaviness of the fihas product.

Table 1. Mean thickness of raw nata de Coco (in mm) at different days of fermentation

\begin{tabular}{|c|c|c|c|}
\hline \multirow{2}{*}{ Treatment } & \multicolumn{3}{|c|}{ Fermentation Days } \\
\cline { 2 - 4 } & 5 Days & 9 Days & 13 Days \\
\hline $\mathrm{T}_{1}$ & 2.57 & 15.92 & $21.96^{\mathrm{a}}$ \\
\hline $\mathrm{T}_{2}$ & 3.21 & 16.81 & $19.09^{\mathrm{b}}$ \\
\hline $\mathrm{T}_{3}$ & 3.02 & 17.30 & $19.66^{\mathrm{b}}$ \\
\hline $\mathrm{T}_{4}$ & 2.71 & 14.95 & $17.23^{\mathrm{c}}$ \\
\hline $\mathrm{T}_{5}$ & 2.65 & 13.30 & $16.46^{\mathrm{c}}$ \\
\hline $\mathrm{ANOVA}$ & $\mathrm{ns}$ & $\mathrm{ns}$ & $* *$ \\
\hline
\end{tabular}

ns $=$ not significant

** = highly significant

\subsection{Wet Weight of Nata de Coco (in g) at Different Days of Fermentation}

A. xylinum was cultured in the medium using pure sucrose and Dorsata honey at different concentrations for 5, 9 and 13 days. Results reveal in Table 2 that at five days of fermentation, the media with pure sucrose, as well as with $1 / 4$ and $1 / 2$ parts Dorsata honey produced almost similar weight. Together, they yielded more substantial weight of BC than the media with Dorsata honey $\geq 3 / 4$. The treatments at 13 days of fermentation obtained the same result as the treatments after five days of fermentation. At nine days of fermentation, the medium with $3 / 4$ part Dorsata honey produced equal weight as pure sucrose and with $1 / 4,1 / 2$ and $3 / 4$ concentrations of Dorsata honey. However, there was an obvious distinction among the three media above in comparison with a medium containing pure sucrose, which produces equal weight as the medium of $3 / 4$ Dorsata honey concentration.

Data prove that using not more than $1 / 2$ of Dorsata honey as carbon source produces very similar weight as pure sucrose as long as the nutrient concentration is sufficient to sustain the growth of $\mathrm{BC}$. The yield of wet $\mathrm{BC}$ increased with an increase in the number of days of fermentation. According to $\frac{15}{}$, nutrient concentration decreases in increasing incubation time. Consequently, on the $14^{\text {th }}$ day, when the nutrient concentration is used up, there was no weight gain of $\mathrm{BC}$ because its production stopped. 
Table 2. Mean wet weight of nata de coco (in g) at different days of fermentation

\begin{tabular}{|c|c|c|c|}
\hline \multirow{2}{*}{ Treatment } & \multicolumn{3}{|c|}{ Fermentation Days } \\
\cline { 2 - 4 } & 5 Days & 9 Days & 13 Days \\
\hline $\mathrm{T}_{1}$ & $695.08^{\mathrm{a}}$ & $835.29^{\mathrm{a}}$ & $910.71^{\mathrm{a}}$ \\
\hline $\mathrm{T}_{2}$ & $698.93^{\mathrm{a}}$ & $813.72^{\mathrm{a}}$ & $914.55^{\mathrm{a}}$ \\
\hline $\mathrm{T}_{3}$ & $702.06^{\mathrm{a}}$ & $808.87^{\mathrm{a}}$ & $887.30^{\mathrm{a}}$ \\
\hline $\mathrm{T}_{4}$ & $631.43^{\mathrm{b}}$ & $744.26^{\mathrm{ab}}$ & $752.92^{\mathrm{b}}$ \\
\hline $\mathrm{T}_{5}$ & $577.29^{\mathrm{b}}$ & $684.62^{\mathrm{b}}$ & $705.66^{\mathrm{b}}$ \\
\hline ANOVA & $* *$ & $* *$ & $* *$ \\
\hline
\end{tabular}

$* *=$ highly significant

\subsection{Dry Weight of BC (in g)}

One $\mathrm{kg}$ of raw nata de coco from each treatment was sun-dried to obtain the dry weight of the BC. Results as shown in Figure 1, prove that the medium containing 3/4 part Dorsata honey produced the heaviest cellulose of $11.83 \mathrm{~g}$, which is $1.18 \%$ of the wet weight of nata. The result reveals that its cellulosic matrix retains the least amount of water. However, an analysis of the differences using LSD showed that the medium above produced a very similar amount of cellulose as the media containing $1 / 2$ and 1 part Dorsata honey. The medium with $1 / 2$ part Dorsata honey does not significantly differ from the medium having the $1 / 4$ part. The medium having pure sucrose as its carbon source is not comparable in weight with the other media. It trapped the most substantial amount of water in the cellulosic matrix, thereby producing the lightest dry BC.

$\mathrm{BC}$ is around $1 \%$ of the total weight of rawnata with the rest being water ${ }^{16}$. Nata-de-coco, being microbial cellulose, is highly hydrophilic, holding water over 100 times its weight ${ }^{14}$. The hydrophilicity of the $\mathrm{BC}$ is due to the abundant hydrogen bond interaction of hydroxyl group, preferentially with water ${ }^{17}$. Nevertheless, the BC content of around 10.72-11.83 $\mathrm{g}(1.07-1.18 \%)$ of the nata with Dorsata honey displays that the mixed carbon source provides a more abundant source of fiber than pure sucrose of approximately $9.57 \mathrm{~g}$ or $0.96 \%$. The result is close to the data recorded in the study of ${ }^{3}$ that the moisture content of the nata produced from sucrose is $92.90 \%$, and presumably, the dried $\mathrm{BC}$ is about $7.1 \%$. The considerable amount of fiber in Dorsata honey-based medium is an indication that it is an ideal dietary component for vegetarians.

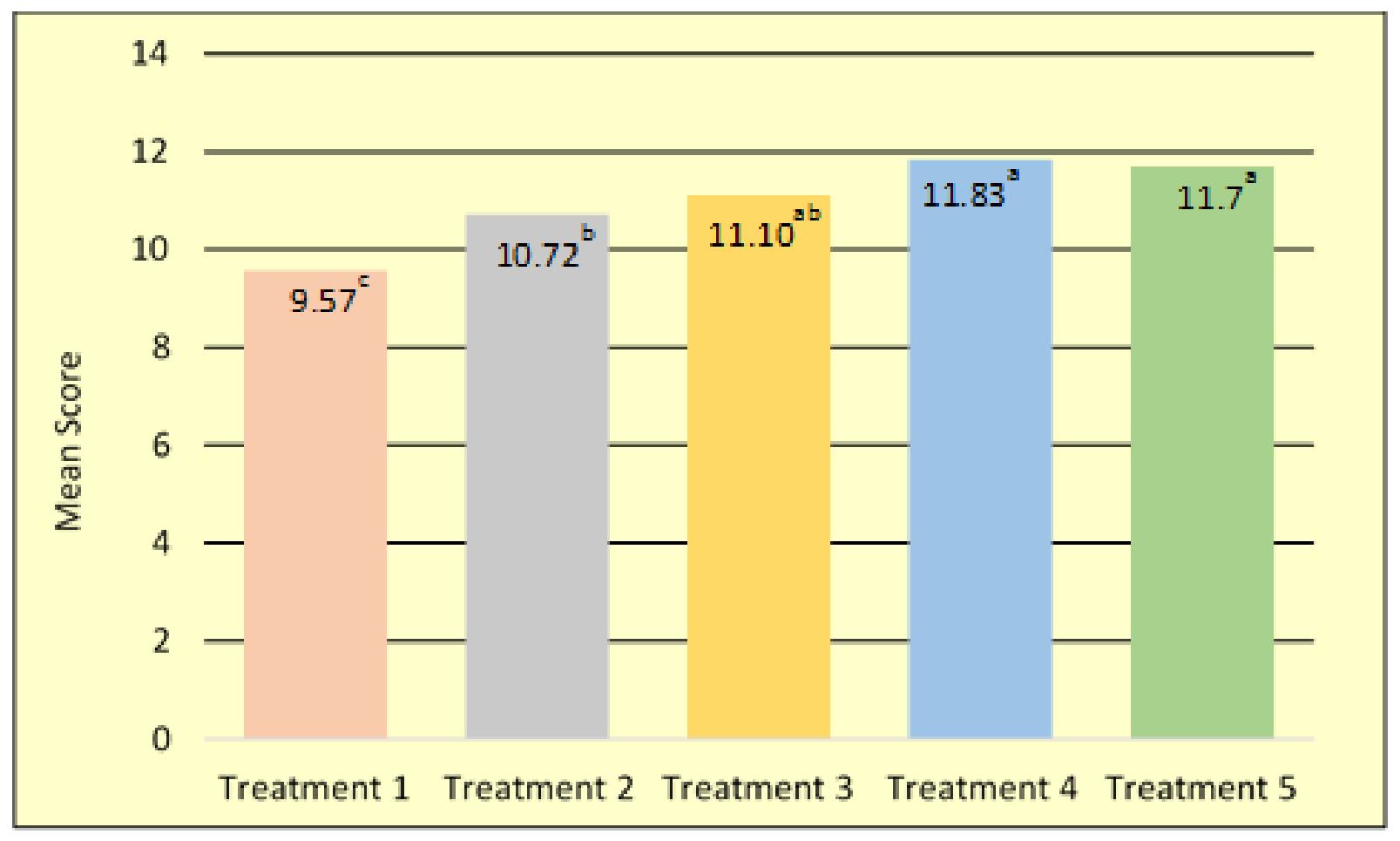

Treatment means carrying the same letter/s are not significantly different.

Figure 1. Dry weight of BC (in g)/kg of raw nata. 


\subsection{Water Absorption Capacity}

The researchers analyzed the water absorption capacity of the edible film only after soaking the raw nata in tap water for nine days. It appears in Figure 2 that the edible film from $1 / 4$ and $1 / 2$ parts Dorsata honey showed the highest water absorption capacity. This result is followed by the control medium, which gained an almost similar amount of water as the media containing $3 / 4$ honey or more. The medium with more than $1 / 2$ part Dorsata honey had the least percent of water increased over nine days test period. The edible film with the highest composition of Dorsata honey produces bacterial cellulose, which exhibited significantly better water resistance properties. It was due to the polymer chain arrangement properties with the hydrophilic and hydrophobic character in the culture medium.

The different culture medium of bacterial cellulose does not only influence the nature of the film but also the physical properties of the edible film comprised of each various culture media ${ }^{\frac{18}{}}$.

\subsection{Solubility of Nata de Coco}

Table 3 shows the comparative solubility of nata de coco. The treatments exhibited the same solubility in all the food-grade solvents used. There were no signs of dispersing actions when suspended in the solutions for ten days. The insolubility of $\mathrm{BC}$ in almost all solvents, including water is due to the interaction of the hydroxyl groups with each other, establishing an intermolecular bond to form crystalline domains $s^{19,20}$. The high number of crystalline areas in $\mathrm{BC}$ contributes to its mechanical strength ${ }^{20}$.

Moreover, the result provides clear proof that nata de coco is cellulosic and not dextran, as was presumed in the past ${ }^{21}$. The insolubility of BC in the form of nata, in the different food-grade solvents tested, lies its importance. The result suggests that the $\mathrm{BC}$ renders its application for research that uses pure cellulose ${ }^{\perp}$. It may also find suitable in food preparation like preserves, pickles, spiked desserts, and other recipes requiring thickening, emulsifying or stabilizing agents.

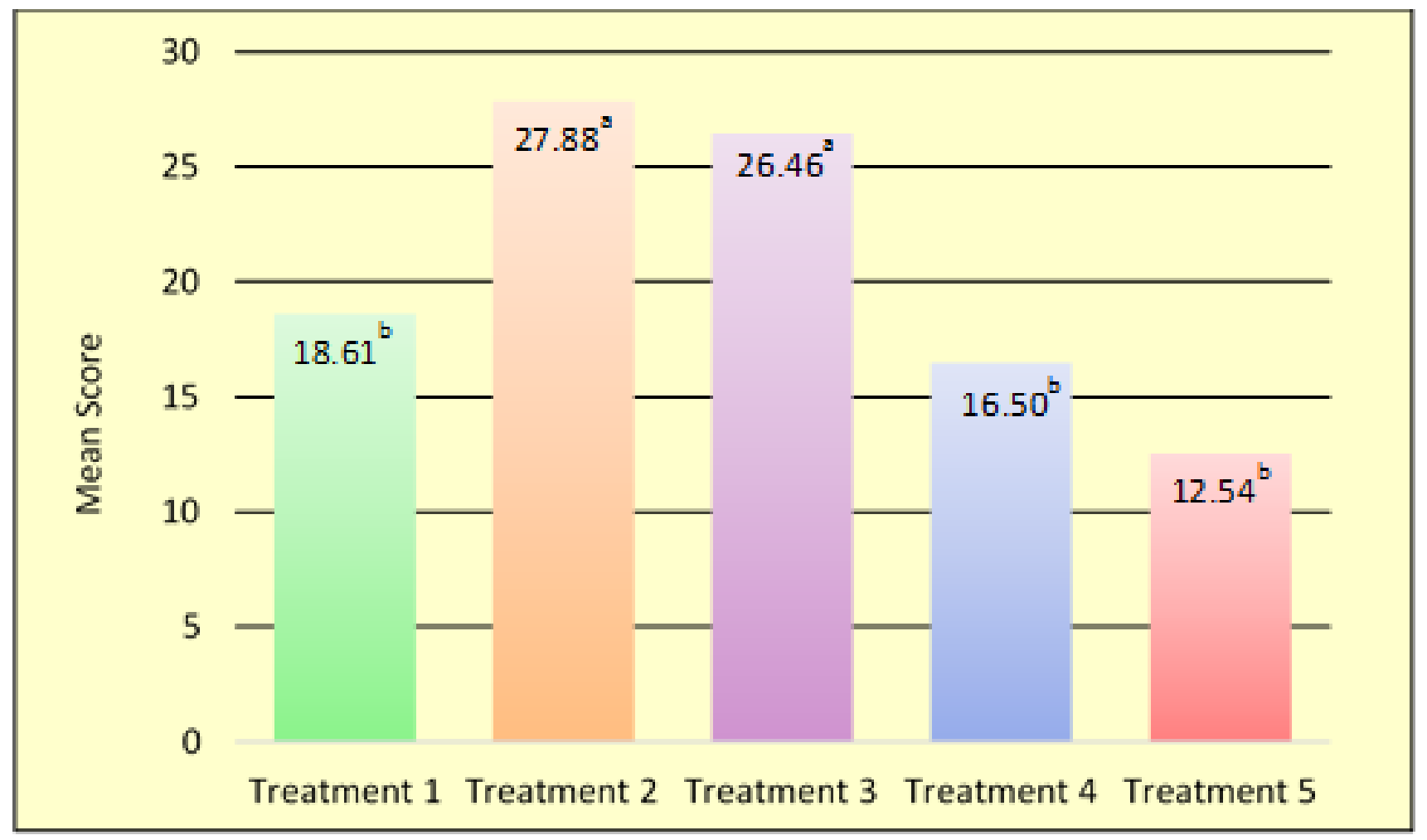

Treatment means carrying the same letter/s are not significantly different.

Figure 2. Percent water absorption of BC. 
Table 3. The solubility of nata de coco in food-grade solvents

\begin{tabular}{|c|c|c|c|c|c|}
\hline Solvents & $\mathrm{T}_{1}$ & $\mathrm{~T}_{2}$ & $\mathrm{~T}_{3}$ & $\mathrm{~T}_{4}$ & $\mathrm{~T}_{5}$ \\
\hline Water & insoluble & insoluble & insoluble & insoluble & insoluble \\
\hline White vinegar & insoluble & insoluble & insoluble & insoluble & insoluble \\
\hline Vegetable glycerin & insoluble & insoluble & insoluble & insoluble & insoluble \\
\hline Ethanol & insoluble & insoluble & insoluble & insoluble & insoluble \\
\hline Propylene glycol & insoluble & insoluble & insoluble & insoluble & insoluble \\
\hline
\end{tabular}

\subsection{Cost Analysis}

As seen in Table 4, one preparation of the control medium could produce about $1,821 \mathrm{~g}$ of raw nata, $1,829 \mathrm{~g}$ for $\mathrm{T}_{2}$, $1,775 \mathrm{~g}$ for $\mathrm{T}_{3} 1,506 \mathrm{~g}$ for $\mathrm{T}_{4}$ and $1,411 \mathrm{~g}$ for $\mathrm{T}_{5}$. Each preparation worked out to be Php 42.60, Php 44.04, Php 45.49, Php 46.93 and Php 48.37, respectively. Amending the medium with $1 / 4,1 / 2,3 / 4$ and 1 part of Dorsata honey correspondingly increased the expenses to $3.38 \%, 6.78 \%$, $10.16 \%$ and $13.54 \%$.
Based on the cost analysis, inclusion of Dorsata honey in the medium significantly increases the expenditure of nata culture. Nonetheless, it is a potential source of fiber that is richer than the sucrose-based medium $\frac{22,23}{2}$ advocate the intake of fiber-rich foods. The consumption of these foods is a more practical approach for reducing costs associated with the management of gut pathophysiology that is accompanied by a considerable financial burden on healthcare services.

Table 4. Cost estimation of medium per preparation

\begin{tabular}{|l|r|r|r|r|r|}
\hline & \multicolumn{1}{|c|}{$\mathrm{T}_{1}$} & \multicolumn{1}{c|}{$\mathrm{T}_{2}$} & \multicolumn{1}{c|}{$\mathrm{T}_{3}$} & \multicolumn{1}{c|}{$\mathrm{T}_{4}$} & \multicolumn{1}{c|}{$\mathrm{T}_{5}$} \\
\hline Grated coconut meat & Php 5.00 & Php 5.00 & Php 5.00 & Php 5.00 & Php 5.00 \\
\hline Mother liquor & 30.00 & 30.00 & 30.00 & 30.00 & 30.00 \\
\hline Glacial Acetic Acid & 4.00 & 4.00 & 4.00 & 4.00 & 4.00 \\
\hline Refined Sugar & 3.60 & 2.70 & 1.80 & 0.90 & - \\
\hline Dorsata Honey & - & 2.34 & 4.69 & 7.03 & 9.37 \\
\hline Total & Php 42.60 & Php 44.04 & Php 45.49 & Php 46.93 & Php 48.37 \\
\hline
\end{tabular}

\section{Conclusion}

Dorsata honey can be an alternative to sucrose in BC production. In countries producing honey from wild honey bees, the study will enable efficient utilization of Dorsata honey. It will also provide a new product dimension to beekeepers that are not getting the right price for their product. Honey-based medium for nata culture produces a more abundant source of fiber than sucrose-based medium; however, it increases the expenditure of nata culture to $3-13 \%$. The insolubility of bacterial cellulose in different food-grade solvents renders it suitable for food preparations that use thickening, emulsifying or stabilizing agents and for research that uses pure cellulose.

\section{Acknowledgment}

The Cagayan State University at Sanchez Mira supported this research. The authors acknowledge the Technical Evaluators, who provided insights and expertise that significantly improved the study.

\section{References}

1. Halib N, Amin MCIM Ahmad I. Physicochemical properties and characterization of nata de coco from local food industries as a source of cellulose. Sains Malaysiana. 2012; 41(2):205-11.

2. Phisalaphong M, Chiaoprakobkij N. Applications and products - nata de coco. Bacterial Nano Cellulose. 2012. p. 143-56. 
3. Gayathry G. Production of nata de coco - a natural dietary fiber product from mature coconut water using Gluconacetobacter xylinum (SJU-1). International Journal of Food and Fermentation Technology. 2015; 5(2):231-5. https://doi.org/10.5958/2277-9396.2016.00006.4

4. Production of nata de coco using soaked soybean water as the alternative usage of $\mathrm{Z}$ wavelzuurAmmoniak (ZA). 2018. https://knepublishing.com/index.php/Kne-Life/article/ view/1656/3904

5. Indrianingsih AW, RosyidaVT, Jatmiko TH, Prasetyo DJ, Poeloengasih CD, Apriyana W, Nisa K, Nurhayati S, Hernawan M, Darsih C, Pratiwi D, Suwanto A, Ratih D. Preliminary study on biosynthesis and characterization of bacteria cellulose films from coconut water. IOP Conference Series: Earth and Environmental Science. 2017; 101(1):1-10. https://doi.org/10.1088/1755-1315/101/1/012010

6. Cerruti P, Roldan P, Garcia RM, Galvagno MA, Varquez A, Foresti ML. Production of bacterial nanocellulose from wine industry residues: Importance of fermentation time on pellicle characteristics. Journal of Applied Polymer Science. 2016; 133(14):1-4. https://doi.org/10.1002/app.43109

7. Zeng X, Small DP, Wan W. Statistical optimization of culture conditions for bacterial cellulose production by Acetobacter xylinum BPR 2001 from maple syrup. Carbohydrate Polymers. 2011; 85(3):506-13. https://doi. org/10.1016/j.carbpol.2011.02.034

8. Bae S, Shoda M. Bacterial cellulose production by fedbatch fermentation in molasses medium. Biotechnology Progress. 2004; 20(5):1366-71. PMid: 15458319. https:// doi.org/10.1021/bp0498490

9. Son C, Chung S, Lee J, Kim S. Isolation and cultivation characteristics of Acetobacter xylinum KJ-1 producing bacterial cellulose in shaking cultures. Journal of Microbiology and Biotechnology. 2002; 12(5):722-8.

10. Ball DW. The chemical composition of honey. Journal of Chemical Education. 2007; 84(10):1643. https://doi. org/10.1021/ed084p1643

11. Terrab A, Vega-Perez JM, Diez MJ, Heredia FJ. Characterization of Northwest Moroccan honeys by gas chromatography-mass spectrometry analysis of their sugar components. Journal of the Science and Food Agriculture. 2002; 82(2):179-85. https://doi.org/10.1002/jsfa.1011

12. Indigenous honeybees in mountain farming systems. 2012. http://chimalaya.org/2012/05/18/indigenous-honeybeesin-mountain-farming-systems/

13. Ouchemoukh S, LouailecheH, Schweitzer P. Physicochemical characteristics and pollen spectrum of some Algerian honey. Food Control. 2007; 18(1):52-8. https://doi.org/10.1016/j. foodcont.2005.08.007
14. Jagannath A, Kalaiselvan A, Manjunatha SS, Raju PS, Bawa PS. The effect of $\mathrm{pH}$, sucrose and ammonium sulphate concentrations on the production of bacterial cellulose (nata-de-coco) by Acetobacter xylinum. World Journal of Microbiology and Biotechnology. 2008; 24:2593-99. https://doi.org/10.1007/s11274-008-9781-8

15. Huynh P, Lin LT, Thanh NN, Bui L, Dung NTP. Investigating the conditions for nata de coco production by newly isolated Acetobacter sp. American Journal of Food Science and Nutrition. 2017; 4(1):1-6.

16. Yamanaka S, Watanabe K, Kitamura N. The structure and mechanical properties of sheets prepared from bacterial cellulose. Journal of Materials Science. 1989; 24(9):3141-5. https://doi.org/10.1007/BF01139032

17. Rebelo AR, Archer AJ, Chen X, Liu C, Yang G, Liu Y. Dehydration of bacterial cellulose and the water content effects on its visco elastic and electrochemical properties. Science and Technology of Advanced Materials. 2018; 19(1):203-11. PMid: 29707063 PMCid: PMC5917443. https://doi.org/10.1080/14686996.2018.1430981

18. Faridah F, Marita Y, Fona Z, Rahmayani R. The effect of culture medium on bacterial cellulose production as edible film material. ASEAN/Asian Academic Society International Conference Proceeding Series; 2012. p. 20-4.

19. Esa F, Tasirin SM, Rahman NA. Overview of bacterial cellulose production and application. Agriculture and Agricultural Science Procedia; 2014. p. 113-9. https://doi. org/10.1016/j.aaspro.2014.11.017

20. Navarra MA, Dal Bosco C, Serra Moreno J, Vitucci FM, Paolone A, Panero S. Synthesis and characterization of cellulose-based hydrogels to be used as gel electrolytes. Membranes. 2015; 5(4):810-23. PMid: 26633528 PMCid: PMC4704013. https://doi.org/10.3390/membranes5040810

21. Iguchi M, Yamanaka S, Budhiono A. Bacterial cellulose - a masterpiece of nature's arts. Journal of Materials Science. 2000; 35(2):261-70. https://doi.org/10.1023/A:1004775229149

22. Abdullah MMH, Gyles CL, Marinangeli CPF, Carlberg JG, Jones PJH. Dietary fiber intakes and reduction in functional constipation rates among Canadian adults: A cost-of-illness analysis. Food and Nutrition Research. 2015; 59:1-10. PMid: 26652739 PMCid: PMC4677277. https:// doi.org/10.3402/fnr.v59.28646

23. Quagliani D, Felt-Gunderson P. Closing America's fiber intake gap communication strategies: From a food and fiber summit. American Journal of Lifestyle Medicine. 2016; 11(1):80-5. PMid: 30202317 PMCid: PMC6124841. https://doi.org/10.1177/1559827615588079 